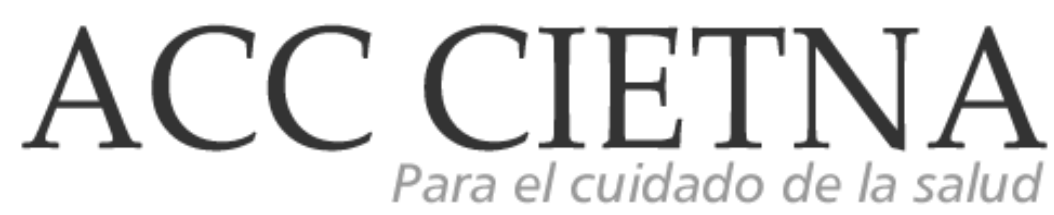

https://doi.org/10.35383/cietna.v3i1.51

\title{
Violência Sexual contra a mulher: Contribuições para a Enfermagem
}

\author{
Rodrigues de Lima Rosileny¹, Ortiz Sanchez Maritza Consuelo², Ribeiro de Castro, Magda ${ }^{3}$, \\ Pereira Marilia de Jesus ${ }^{4}$
}

\section{INFORMACIÓN DEL ARTÍCULO \\ Historia del artículo:}

Recibido el 15 de noviembre de 2016

Aceptado el 15 de febrero de 2016

\section{Palabras claves:}

Enfermagem

Saúde da mulher

violência sexual

\section{RESUMEN}

Esta investigación tiene como objeto la visión del estudiante universitario frente a la mujer en situación de violencia sexual. Objetivos: Describir la comprensión sobre violencia sexual; analizar las acciones para minimizar la violencia sexual contra la mujer; verificar las acciones de los académicos en lo que se refiere a la mujer en situación de violencia sexual. Investigación cualitativa; colaboradores: 10 académicos de los diversos cursos de una Institución de enseñanza Superior Privada de la ciudad de Río de Janeiro. Los datos muestran que algunos colaboradores no tienen claridad sobre el significado de violencia sexual y lo asocian con la acción de violación.

Sin embargo una gran mayoría consigue distinguirla de los demás tipos de violencia. Los profesionales de salud, especialmente los enfermeros, deben realizar orientaciones en salud sobre las formas de prevención de este tipo de violencia, favorecer la recepción solidaria y estimular la notificación, posibilitando una intervención profesional humanizada, contribuyendo para garantizar sus derechos, autonomía y autoestima de la mujer victimizada.

\footnotetext{
${ }^{1}$ Enfermeira do Hospital Israelita. Rio de Janeiro. Brasil. Email: morsa_peru@yahoo.com

2 Doutora em Enfermagem, Professora Adjunta do Departamento de Enfermagem Fundamental da Escola de Enfermagem Aurora de Afonso Costa da Universidade Federal Fluminense. Niterói. Rio de Janeiro. Brasil. Email: mortiz@gmail.com

${ }^{3}$ Doutora em Enfermagem, Professora Adjunta do Departamento de Enfermagem Fundamental da Escola de Enfermagem Aurora de Afonso Costa da Universidade Federal Fluminense. Niterói. Rio de Janeiro. Brasil. Email: magnarcastro@ig.com.br

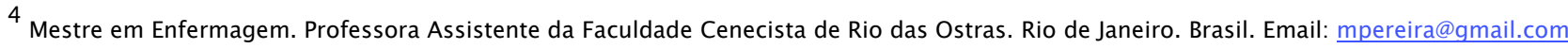


Sexual Violence against women: Contributions for Nursing

\section{ABSTRACT}

Keywords:

Nursing

Women's health

Sexual violence.
This study's purpose is student university look forward to women in situations of sexual violence. Objectives: To describe the understanding of sexual violence; Analyze the actions to minimize sexual violence against women; check the actions of academics related to women in situations of sexual violence. Qualitative research; whose collaborators 10 students of various courses of an institution of Private Higher Education the city of Rio de Janeiro. The findings show that some respondents did not have clarity on the meaning of sexual violence and rape associate with the action. However a large majority can distinguish it from other types of violence. Health professionals, especially nurses, should carry health guidance on ways to prevent this type of violence, promote solidarity with and encourage reporting, enabling a humanized profesional intervention, contributing to ensuring the rights, autonomy and self-esteem of victimized woman.

\section{Introdução}

Esta pesquisa tem por objeto de estudo o olhar do estudante universitário frente à mulher em situação de violência sexual. A violência representa uma dasprincipais causas de morbidade e mortalidade entre a população jovem. Enquanto os homicídios ocorrem em espaços públicos atingindo principalmente o sexo masculino, a violência sexual afeta o sexo feminino dentro do espaço doméstico. Mulheres em situação de violência sexual experimentam sequelas físicas e psicológicas, tornando-se mais vulneráveis a diversos problemas de saúde'.

A violência sexual é uma demonstração de poder do homem sobre a mulher, não decorrente do desejo amoroso. Essa agressão focalizada na sexualidade da mulher atinge seu ser por completo. As marcas físicas e psicológicas da violência sexual são frequentemente graves, não se tratando apenas de ferimentos, infecções sexualmente transmitidas ou gravidez não desejada. O uso da coação psicológica é muito frequente em diversos casos, sendo uma forma do agressor confundir e criar situações de grande ansiedade e angústia na vítima².

Segundo a Organização Mundial da Saúde (OMS), o abuso físico ou sexual resulta em elevadas taxas de problemas de saúde nas mulheres. Elas têm uma probabilidade $16 \%$ maior de ter um bebê com baixo peso ao nascer, chance duas vezes maior de ter aborto, probabilidade quase duas vezes maior de sofrer depressão e, em algumas regiões, a chance de contrair o Vírus da Imunodeficiência Humana (HIV) é 1,5 vezes maior em relação àquelas que não sofreram esse tipo de violência. Além disso, a propensão para o desenvolvimento de transtornos por consumo de álcool e de ansiedade é 2,3 e 2,6 vezes maior entre as mulheres que sofreram violência física e/ou sexual, respectivamente 3 .

Aproximadamente 12 milhões de pessoas a cada ano no mundo são atingidas pela violência sexual. Dentro dessa estatística, se encontram sob-risco da violência sexual, mulheres agredidas fisicamente pelos parceiros 1 . 
Pesquisas realizadas com enfoque nas violências que vitimam as mulheres apresentam resultados devastadores, tais como o desequilíbrio de sua saúde mental e física, aumentando o risco, em longo prazo, da manifestação de outros problemas como cefaléias crônicas, alterações físicas, alterações gastrintestinais, dor pélvica, abuso de drogas, álcool e depressão. Cabe mencionar que esse problema afeta, além da mulher, os familiares envolvidos, a economia do país e as sociedades de forma geral 1,4 .

No que diz respeito à violência sexual, entende-se que os crimes sexuais são classificados como Crimes Contra a Dignidade Sexual, envolvendo crimes contra a liberdade sexual e classifica o estupro como $o$ ato de constranger alguém, mediante violência ou grave ameaça, a ter conjunção carnal ou a praticar ou permitir que com ele se pratique ato libidinoso; violação sexual mediante fraude e assédio sexual. É importante salientar que a violencia doméstica, sexual e/ou psicológica contra a mulher é uma violação dos direitos humanos, já que está presente em diversos contextos e circunstâncias, se caracterizando como um grave problema de saúde pública mundial, inclusive no Brasil5.

No Brasil o Sistema Nacional de Notificação de Agravos (SINAN) no ano de 2011 , registrou no país 73.633 atendimentos, 48.152 destes casos eran mulheres $(65,4 \%)$ (Waiselfisz, 2011). Apesar da implantação da notificação compulsória no Brasil, a denúncia às autoridades policiais e a procura por ajuda médica são baixas ${ }^{6}$.

Ressalta-se que diante das diversas situações de violência contra a mulher, sancionou-se a Lei Maria da Penha, que cria mecanismos para coibir a violência doméstica e familiar contra a mulher, nos termos do $\S 8^{\circ}$ do art. 226 da Constituição Federal. Esta lei recebeu o nome de "Lei Maria da Penha" como forma de homenagear a mulher Maria da Penha Fernandes, símbolo da luta contra a violência familiar e doméstica?
Dessa forma, após o reconhecimento das situações supracitadas, elaboramos os seguintes objetivos:

- Identificar o entendimento dos acadêmicos sobre violência sexual.

- Descrever as ações propostas pelos acadêmicos para minimizar a violência sexual contra a mulher.

- Verificar as ações dos acadêmicos referentes à mulher em situação de violência sexual.

O presente trabalho contribuirá para um melhor entendimento das formas de abordagem da mulher vítima de violência sexual, bem como a assistência de enfermagem, considerando as prioridades e necessidades desta população.

\section{Método}

Trata-se de um estudo de natureza qualitativa; nesta perspectiva, a parte operacional da pesquisa teve como base a descrição e análise de dados referentes ao objeto investigado. A pesquisa qualitativa preocupa-se com um nível de realidade que não pode ser quantificado, ou seja, trabalha com o universo de significados, motivos, aspirações, crenças, valores e atitudes ${ }^{8}$.

Os colaboradores do presente estudo foram dez (10) alunos de uma Instituição de Ensino Superior da cidade do Rio de Janeiro dos seguintes cursos: Administração (01), Educação Física (05), Enfermagem (01), Engenharia Ambiental (01), Engenharia de Produção (01) e Fisioterapia (01), com idades variadas de 21-30 anos (08), 31-40 anos (01) e 41-50 anos (01). Os mesmos assinaram o Termo de Consentimento Livre e Esclarecido, garantindo o sigilo e o anonimato respeitando os princípios éticos da pesquisa com seres humanos de acordo com a Resolução 466/2012 do Conselho Nacional de Saúde 9 .

Visando garantir o anonimato dos entrevistados, optou-se pelo uso do termo Colaborador e a identificação do curso ao qual o acadêmico está vinculado. 
Para coleta dos dados aplicou-se entrevista semiestruturada, uma vez que a entrevista expressa uma relação entre sujeito e participante: entrevistador e entrevistado, possibilitando uma relação recíproca, em que depoente e pesquisador interagem constantemente, permitindo ao pesquisador a captação imediata e coerente da informação ${ }^{10}$.

A entrevista semiestruturada combina perguntas fechadas e abertas, tendo o entrevistado a possibilidade de discorrer sobre o tema proposto, sem respostas ou condições pré-fixadas pelo pesquisador, que mantém um elevado grau de flexibilidade na exploração das quest ões pertinentes ao objeto do estudo. Esta técnica nos possibilitou enumerar, de forma mais abrangente, as questões abordadas a partir dos objetivos ou pressupostos, advindos, obviamente, da definição do objeto de investigação ${ }^{10}$.

Após o término da entrevista, procedeu-se à ordenação dos dados, perpassando pela transcrição, leitura e releitura do material para tornar viável a organização dos achados com o objetivo de apreender as falas dos sujeitos para a descoberta dos núcleos de sentido ${ }^{8}$, originando as categorias temáticas do estudo.

\section{Resultados e discussão}

A partir da análise das entrevistas, emergiram as seguintes categorias: entendimento sobre violência sexual acometida contra a mulher; propostas para minimizar/erradicar a violência sexual contra a mulher; e ações dos acadêmicos frente à mulher em situação de violência sexual.

\subsection{Entendimento sobre violência sexual}

A esse respeito, temos alguns depoimentos que fazem referência sobre o tema nos seguintes termos:

Violência sexual é o ato de impor seus desejos sexuais sem a autorização do outro [...]. (Colaborador 1 - Enfermagem)
[...] É quando você está sendo forçada a fazer alguma coisa [...]. (Colaborador 2 - Engenharia Ambiental)

[...] é tudo o que for sem consentimento [...].

(Colaborador 3 - Educação Física)

A violência sexual eu entendo como agressão física à mulher e a forçação do ato sexual. (Colaborador 5 - Educação Física).

[...] é o ato forçado entre duas pessoas [...]. (Colaborador 8 - Educação Física)

Evidencia-se nos discursos que os sujeitos entendem a violência sexual como um ato que envolve força, agressão, imposição do desejo de uma pessoa sobre outra.

Coadunando com esse pensamento, a literatura define violência como a imposição de dor e sofrimento evitáveis; entretanto, o conceito é mais amplo e ambíguo do que essa mera constatação, já que a dor é um conceito difícil de ser definido. A cada ano mais de 1,6 milhões de pessoas no mundo perdem suas vidas em função da violência, que está entre as principais causas de morte de pessoas entre 15 e 44 anos no mundo inteiro, representando $14 \%$ das mortes entre os homens e $7 \%$ das mortes entre as mulheres, o que determina um peso enorme nas economias nacionais a cada ano em cuidados de saúde, aplicação da lei e perda de produtividade ${ }^{1}$.

Atualmente, a violência baseada no gênero além de ser uma das mais disseminadas violações dos direitos humanos é um dos problemas de saúde pública no mundo, afetando uma a cada três mulheres. A desigualdade de gênero também é sofrida devido ao status social subordinado na sociedade. $O$ alto índice de violência sexual acometida contra a mulher é uma das maiores causas de morbidade em mulheres jovens em idade reprodutiva, sendo caracterizada por uma questão histórica e cultural ${ }^{12}$. 
Entende-se violência sexual como qualquer ação quetenha tentativa de obter um ato sexual indesejado, comentários sexuais, ou atos contra a sexualidade de uma pessoa, utilizando a coerção, ameaças por qualquer pessoa independentemente da relação com a vítima, não se limitando apenas a casa ou ao trabalho' ${ }^{11}$. Considera-se, igualmente, a ação de constranger um indivíduo a presenciar, manter ou participar de uma relação sexual não desejada, com imposição de intimidação, ameaça, coação ou uso da força ${ }^{6}$.

Além do supracitado, a Lei Maria da Penha no que diz respeito às formas de violência doméstica e familiar contra a mulher, entende a violência sexual como qualquer conduta que induza a mulher a comercializar ou utilizar sua sexualidade, assim como o impedimento do uso de qualquer método contraceptivo, a imposição do matrimônio, da gravidez, do aborto ou da prostituição, mediante coação, chantagem, suborno ou manipulação, ou qualquer ato que demonstre limitação ou anulação do exercício de seus direitos sexuai se reprodutivos ${ }^{5}$.

Importante ressaltar que a violência sexual pode comprometer a saúde física e mental da mulher, causando traumas que podem ser consequentes de uma gravidez indesejada, doenças sexualmente transmissíveis, uso da força física ocasionando hematomas e/ou traumatismos graves, além de poderem resultar na morte da vítima'.

Ao abordar o estupro, como uma forma de violência, destaca-se que meninas adolescentes e mulheres jovens no Brasil e no mundo são as mais vulneráveis.

A maioria dos crimes decorrentes da violência se torna difícil de ser denunciado devido ao agente ser um parente, pessoa próxima ou conhecida.

Estatísticas apontam que menos de $10 \%$ dos casos são registrados nas delegacias 1 .

Observou-se que alguns colaboradores da pesquisa associam a violência sexual ao estupro:
[...] é estupro [...]. (Colaborador 2 - Engenharia Ambiental)

Violação da mulher e estupro. (Colaborador 9 Fisioterapia)

[...] estupro [...]. (Colaborador 10 - Administração) [...] é o estupro. (Colaborador 6 - Engenharia de Produção)

Nesse sentido, autores afirmam que a violencia sexual envolve estupro, atos obscenos, carícias não consentidas, sexo forçado na relação conjugal ${ }^{13}$. Atualmente, o estupro é considerado, em seu sentido amplo, o constrangimento de alguém mediante violência ou grave ameaça, a ter conjunção carnal ou a praticar ou permitir que com ele se pratique ato libidinoso. É um ato que deve ser entendido como a negação de autonomia das mulheres sobre seus corpos ${ }^{11}$, podendo observar que alguns homens tomam a mulher como posse, usando-as como símbolo de conquista e extremo poder perante a sociedade ${ }^{4}$.

A violência sexual se manifesta quando o homem obriga a mulher a ter relações sexuais com ele ou com outros, ou a força a práticas sexuais que não a agradam. Nos crimes sexuais a mulher tem seu corpo, sua vontade e seus direitos negados, em uma demonstração de brutalidade extrema do homem sobre a mulher. Muito dessa espécie de violência é silenciada, pois entre o casal é "aceitável" ceder ao seu homem, mesmo quando não se está sexualmente e/ou emocionalmente disposta. Mais uma vez a mulher se subjuga não somente ao homem, mas a cultura que a violenta.

Nos relatos, a seguir, podemos observar que atitudes como agarrar ou beijar sem o consentimento da pessoa também se configura violência sexual:

[...] É um beijo forçado, passarem a mão em você sem seu consentimento [...]. (Colaborador 2 Engenharia Ambiental) 
[...] violência sexual seria um beijo, um abraço, uma carícia sem o consentimento da pessoa. (Colaborador 3 - Educação Física)

[...] forçar um beijo ou carícia [...]. (Colaborador 8 - Educação Física)

\subsection{Propostas para minimizar/erradicar a} violencia sexual contra a mulher

Algumas propostas estão em vigor para minimizar ou erradicar a violência contra a mulher, entre elas destaca-se a Lei Maria da Penha, que, ao mencioná-la, os sujeitos consideram que esta lei defende a mulher conferindo proteção à mesma.

[...] o aspecto principal é defender o bem-estar da mulher [...]. (Colaborador 1 - Enfermagem)

[...] procura defender a mulher contra a violência [...]. (Colaborador 3 - Educação Física)

Ela defende os interesses da mulher [...], se é uma agressão física, se é uma agressão sexual [...]. (Colaborador 7 - Educação Física)

A lei supra citada acolhe as mulheres protegendo legalmente a vítima de violência doméstica e familiar, dispondo sobre a criação dos Juizados de Violência Doméstica e Familiar contra a Mulher e de outros tratados internacionais ratificados pela República Federativa do Brasil, e estabelece medidas de assistência e proteção às mulheres em situação de violência doméstica e familiar ${ }^{5}$.

Ainda a respeito da lei em discussão, outros colaboradores acrescentaram:

[...] acredito que a lei veio pra ajudar as mulheres que sofrem esse tipo de agressão e realmente não tinham uma ajuda do governo, do Estado. Isso era meio que normal uma mulher ser violentada, machucada, não só sexualmente, mas ser agredida e isso ficar impune. (Colaborador 4 - Educação Física)
[...] a lei aborda qualquer tipo de violência, seja ela moral, física, psicológica, doméstica (Colaborador 1 - Enfermagem)

Nesse contexto, tais sujeitos estão em conformidade com o redigido na lei, ao identificar algumas formas de violência, tais como violência doméstica e familiar, violência física, psicológica, sexual, patrimonial e moral ${ }^{5}$.

Entretanto, alguns depoentes manifestaram desconhecimento ou pouco conhecimento sobre esta lei.

[...] não conheço muito a fundo [...] acho que vem um grupo para ajudar [...] não sei muito bem [...]. (Colaborador 2 - Engenharia Ambiental)

[...] olha, eu não tenho um conhecimento muito grande sobre o assunto [...]. (Colaborador 5 Educação Física)

[...] eu ouvi falar [...], mas não conheço, não sei até que área ela abrange [...] o tipo de punição. Nesse ponto eu desconheço. (Colaborador 7 - Educação Física)

Não, não conheço. (Colaborador 8 - Educação Física)

Tais relatos chamam atenção para a necessidade da difusão no meio acadêmico de discussões acerca da violência sexual contra a mulher e da aplicabilidade da Lei Maria da Penha, enfatizando aspectos de proteção à mulher e a representação legal e jurídica frente aos órgãos responsáveis de zelar pela mesma.

Deve ser igualmente objeto de esclarecimento questões de denúncia, retirada de queixas, dentre outras, visto que este procedimento só poderá ser executado perante o juiz:

[...] não tem como ela tirar essa queixa, só perante o juiz [...]. (Colaborador 6 - Engenharia de Produção) 
3.3. Ações dos acadêmicos frente à mulher em situação de violência sexual

Pode-se observar que a maioria dos entrevistados desconhece a prioridade no atendimento à mulher vítima de violência sexual. Entretanto, os mesmos expõem através de seus depoimentos que este tipo de violência é um assunto que deve ser encaminhado para as delegacias ou órgãos competentes para a resolução do problema.

[...] dependendo do estado físico dela, a encaminharia ao hospital para exames, para uma averiguação ou então a encaminharia até uma delegacia para que denuncie a agressão. (Colaborador 1 - Enfermagem)

[...] agora existe uma delegacia da mulher [...] aconselharia a pessoa ir à delegacia [...]. (Colaborador 2 - Engenharia Ambiental)

[...] a levaria para uma delegacia, um órgão competente [...]. (Colaborador 3 - Educação Física)

[...] delegacia da mulher para fazer uma denuncia [...].

(Colaborador 4 - Educação Física)

[...] eu a levaria para a polícia. (Colaborador 5 Educação Física)

[...] daria instruções para procurar uma delegacia [...].

(Colaborador 6 - Engenharia de Produção)

[...] ir à delegacia e levar o assunto adiante.

(Colaborador 7 - Educação Física)

[...] a ajuda de um policial. Delegacia. (Colaborador 8 - Educação Física)

[...] indicaria ela ir à polícia. (Colaborador 9 Fisioterapia)

Importante salientar que o caminho a ser percorrido pela mulher agredida no primeiro momento deve ser procurar um Pronto Socorro e registrar na ficha de atendimento o ato da agressão; posteriormente, dirigir-se à Delegacia da Mulher ou à Delegacia de Polícia mais próxima para o registro de um Boletim de Ocorrência (B.O.) e conduzida ao Instituto Médico Legal (IML), onde será realizado o exame de corpo delito ${ }^{13}$.

$\mathrm{O}$ atendimento à vítima de violência sexual tem os seguintes objetivos: atenção médica; registro adequado das lesões; preservação de possíveis provas que poderão ser importantes posteriormente; prevenção de Doenças Sexualmente Transmissíveis, inclusive HIV, e prevenção de gravidez indesejada, através da contracepção de emergência ${ }^{13}$.

$\mathrm{Na}$ mesma linha de pensamento, observamos que a mulher vítima de violência sexual deve ser acolhida em sua totalidade, realizar exame físico completo, dentre eles o exame ginecológico, ter suas lesões tratadas, realizar coleta de amostras para diagnóstico de infecções genitais e coleta de material para identificação do agressor ${ }^{1}$.

Para isto, os profissionais de saúde deverão ser sensibilizados (as) e capacitados (as), para trabalhar no enfrentamento da violência, investigando e/ou levantando dados sobre a história da mulher, com ênfase na situação de violência sexual (quem, quando, onde e como aconteceu); as providências já tomadas pela mulher ou pela família, o que possibilitará realizar o diagnóstico e planejamento das ações coerentes com as necessidades encontradas. Entre outras ações a realizar deve estar a orientação, para que a mesma registre a ocorrência, entretanto, não deverá ser obrigada'.

Se a mulher estiver grávida ou suspeitando de gravidez, deve-se considerar claramente a demanda trazida por ela, focalizada nos seguintes aspectos: identificação do desejo de interrupção da gravidez ou não, discussão a respeito dos direitos legais já garantidos à mulher, existência de valores morais e religiosos que possam determinar ou influenciar a decisão da mulher e a 
discussão de alternativas tais como: interrupção da gravidez, entrega da criança para adoção, realização de pré-natal, identificação de redes de apoio à mulher e caracterização do perfil socioeconômico da mesma ${ }^{1}$.

Nos últimos anos, múltiplos esforços, na maior parte dos países, têm procurado modificar a resposta dos serviços de saúde aos casos de violência, situação que, por sua complexidade, exige um engajamento multidisciplinar, isto é, a contribuição de diferentes profissionais, setores sociais, comunitários e dos governos nacional e local'2.

Apesar desse esforço, ainda observa-se que a maioria dos serviços de saúde não está equipada suficientemente para diagnosticar, tratar e contribuir para a prevenção dessa ocorrência. Em geral, os serviços carecem de profissionais treinados no reconhecimento dos sinais da violência, principalmente aquela de caráter mais insidioso. Esse diagnóstico requer uma rede de apoio, que extrapola os serviços de saúde, para que os problemas identificados sejam resolvidos ${ }^{1}$.

Além de algumas dificuldades do sistema de saúde, podemos nos deparar com diversos juízos de valores, que o individuo desenvolve e age de acordo com sua própria visão de mundo:

[...] vou fazer minha análise [...] porque tem muita mul her dissimulada. ( Col abor ador 10 -

Administração)

A violência contra as mulheres é o resultado de uma ideologia de dominação masculina, que é produzida e reproduzida tanto por homens como por mulheres. A violência é uma ação que transforma diferenças em desigualdades hierárquicas com o fim de dominar, explorar e oprimir. A ação violenta trata o ser dominado como "objeto" e não como "sujeito", o qual é silenciado e se torna dependente e passivo.
Nesse sentido, o ser dominado perde sua autonomia, ou seja, sua liberdade, entendida como "capacidade de autodeterminação para pensar, querer, sentir e agir"14.

A violência contra a mulher é inaceitável e deve ser reiterada como um problema de saúde pública que tem como pano de fundo algumas desigualdades sociais, como renda e escolaridade. Além de um esforço contínuo no sentido da redução das relações assimétricas entre homens e mulheres, que envolvem por vezes discriminação e preconceito, ações relacionadas à prevenção devem ser priorizadas e desempenhadas pelos diversos setores da sociedade, assim como a redução das desigualdades sociais associadas a sua ocorrência².

Cabe ressaltar que um estudo divulgado pelo Instituto de Pesquisas Econômicas Aplicadas (IPEA) refere que a maioria dos brasileiros ainda considera a mulher como responsável pela violência sexual. Ainda aponta que, para $42,7 \%$ dos brasileiros "mulheres que usam roupas que mostram o corpo merecem ser atacadas".

Segundo a ONU a violência contra as mulheres não está confinada a uma cultura, uma região ou um país específicos, nem a grupos de mulheres em particular dentro de uma sociedade. As raízes da violencia contra as mulheres decorrem da discriminação persistente contra as mulheres.

\section{Considerações Finais}

O present e est udo demonst ra que al guns entrevistados não têm clareza sobre o significado de violência sexual e a associam com a ação de estupro. Contudo, uma grande maioria consegue distinguir a violência sexual dos demais tipos de violência.

Apesar da divulgação da mídia em relação à Lei Maria da Penha, alguns depoentes relatam que não a conhecem, entretanto, grande parte dos 
entrevistados conseguiu informar os aspectos principais da Lei.

As propostas apontadas pelos participantes para a mulher em situação de violência sexual foram: o encaminhamento aos hospitais e as Delegacias Especializadas no Atendimento à Mulher como uma forma de resolver o problema da mulher vítima deste tipo de violência.

Para os profissionais de saúde, especialmente os enfermeiros, sugere-se a realização de capacitação sobre as formas de prevenção deste tipo de violência, favorecer o acolhimento solidário e encorajar a notificação, ou seja, promover uma intervenção profissional humanizada, capaz de contribuir na garantia dos direitos, autonomia e autoestima da mulher vitimizada. Negligenciar esses aspectos representa uma imperdoável manifestação de descaso e de abandono.

Fazem-se necessárias ações frente a essa ocorrência, uma vez que a violência contra a mulher caracteriza-se como fenômeno social de grande magnitude que, naatualidade, tem se tornado evidente, configurandodesafios a todos os envolvidos com essa problemática.

\section{Referências}

1. Ministério da Saúde. Secretaria de Atenção à Saúde. Área Técnica de Saúde da Mulher.

Prevenção e tratamento dos agravos resultantes da violência sexual contra mulheres e adolescentes. 2. ed. Atualizada e ampliada. Brasília: Ministério da Saúde, Brasil: Norma Técnica, 2005

2. Lamarca G, Vettore M. Série: Violência contra a mul her: um probl ema de proporções epidêmicas. Rio de Janeiro: Portal DSS Brasil; [acesso em 27 Set 2014]. Disponível em: http://dssbr.org/site/2014/03/violenciacontraa-mulher-um-problema-de-proporcoes epidemicas.
3. Oliveira EM. Fórum: violência sexual e saúde. Introdução. Cad Saúde Públ. 2007; 31 (2)

4. Vilella WV, Lago T. Conquistas e desafios no atendimento das mulheres que sofreram violência sexual. Cad saúde publ. 2007; 23(2):

471-5.

5. Presidência da Republica. Casa civil. Subchefia de assuntos jurídicos. Lei $n^{0} 12.015$, de 2009. [acesso em 10 mar 2014]. Disponível em: http://www.planalto.gov.br/ccivil_03ato2007 2010/2009/lei12015.htm/

6. Oshikata, C. T. et al. Características das mulheres violentadas sexualmente e da adesão ao seguimento ambulatorial: tendencias observadas ao longo dos anos em um serviço de referência em Campinas, São Paulo, Brasil. Cad. Saúde Pública, v.27, n.4. Rio de Janeiro, abr. 2011.

7. Congresso Nacional (Br). Lei $\mathrm{n}^{\circ} 11.340$, de 7 de Agosto de 2006. [acesso em 10 mar 2014]. Disponível em: http:/ / www.planalto.gov.br/ccivil_03/_ato20042006/2006/lei/I11340.htm

8. Minayo MCS. Pesquisa Social: teoria, método e criatividade. $6^{\text {a }}$ ed. Petrópolis: Vozes; 2008.

9. Ministério da Saúde (Br). Resolução 466/12 do Conselho Nacional de Saúde sobre Diretrizes e Normas Regulamentadoras de Pesquisa envolvendo seres humanos. Diário Oficial da União, Brasília (DF).

10. Manzini EJ. Considerações sobre a elaboração de roteiro para entrevista semi-estruturada. In: Marquezine MC, Almeida MA, Omote S, organizadores. Colóquios sobre pesquisa em educação especial. Londrina: Eduel; 2003. p.1125.

11. Organização Mundial da Saúde. Violência e prevenção de lesões e incapacidades (VIP). Prevenção primária do parceiro íntimo: violência e 
violência sexual. 2010. [acesso em 10 mar2014]. Disponível em:

http://www.who.int/violence_injury_prevention/

12. Bedone $A J$, Faúndes $A$. Atendimento integral às mulheres vítimas de violência sexual: Centro de Assistência Integral à Saúde da Mulher, Universidade Estadual de Campinas. Cad. Saúde Pública [online] $2007 \mathrm{fev}$ [acesso em 10 mar 2014]; 23(2): 465-469. Disponível em: http:/ / www.scielosp.org/pdf/scp/v23n2/24.pdf 13. Lacerda E, coordenador. Promoção da saúde no combate à violência. Revista Promoção da Saúde. 2002; 3(6): 71-3.

14. Chauí, Marilena. "Participando do Debate sobre Mulher e Violência". In: Franchetto, Bruna, Cavalcanti, Maria Laura V. C. e Heilborn, Maria Luiza (org.). Perspectivas Antropológicas da Mulher 4, São Paulo, Zahar Editores, 1985. 